\title{
Evidence of higher insulin resistance in NIDDM patients with ischaemic heart disease
}

\author{
S.Inchiostro, G. Bertoli, G.Zanette, V.Donadon \\ Diabetic Clinic and Third Internal Medicine, S. Maria degli Angeli Hospital, Pordenone, Italy
}

Summary Prospective studies have shown a relationship between hyperinsulinaemia, an indirect index of insulin resistance, and IHD in men with normal glucose tolerance. In NIDDM this association is less clear possibly due to the poor significance of insulin and Cpeptide concentrations as an index of insulin resistance. Therefore, only a direct measurement of insulin sensitivity could clarify the possible relationship between insulin resistance and IHD in NIDDM. We have evaluated insulin sensitivity, by means of an ITT, and some risk factors for IHD in 72 men with NIDDM, 36 with and 36 without IHD, attending our out-patient Diabetic Clinic. The two groups were of similar age, duration of diabetes, glycaemic control and body composition. Subjects with IHD were more insulin resistant $\left(\mathrm{K}_{\mathrm{ITT}}\right.$ index $2.45 \pm 0.18$ vs $3.12 \pm 0.13 \%$ per min, in patients with and without IHD, respectively, $p<0.004)$, had higher total $(p=0.011)$ and LDL serum cholesterol levels $(p=0.010)$ and greater prevalence of hypertension $(p=0.001)$ compared to sub- jects without IHD. Using step-wise logistic regression analysis, insulin resistance (odds ratio $2.57,95 \% \mathrm{CI}$ 1.87-3.28, $p=0.008$ ), hypertension (odds ratio 8.17, $95 \%$ CI $6.86-9.48, p=0.002$ ), total serum cholesterol levels (odds ratio 1.02, 95\% CI 1.005-1.035, $p=0.015$ ) and BMI $(0.79,95 \%$ CI $0.67-0.97, p=0.049)$ were independently associated with IHD. After adjustment for age and duration of diabetes, only insulin sensitivity was directly related to the age of onset of IHD, independently from other clinical and metabolic parameters $(p<0.015)$. In conclusion: in NIDDM, patients with IHD are more insulin resistant compared to subjects without IHD. Insulin resistance is associated with IHD, independently from other cardiovascular risk factors. A higher insulin resistance seems to be related to an earlier clinical onset of IHD. [Diabetologia (1994) 37: 597-603]

Key words Hyperinsulinaemia, insulin resistance, insulin tolerance test, ischaemic heart disease, NIDDM.
Three prospective studies have shown an independent association between hyperinsulinaemia and IHD in men with normal glucose tolerance [1-3]. Some crosssectional studies have confirmed these results [4-7] whereas others have shown less clear conclusions [8]. In NIDDM some reports have revealed an inde-

Received: 30 August 1993

and in revised form: 28 December 1993

Corresponding author: Dr. S. Inchiostro, S. Marco, 2019, I-30124 Venezia, Italy

Abbreviations: NIDDM, non-insulin-dependent diabetes mellitus; IHD, ischaemic heart disease; ITT, insulin tolerance test; CI, confidence interval; $\mathrm{ACE}$, angiotensin-converting-enzyme pendent relationship between hyperinsulinaemia or higher C-peptide serum levels and IHD [9-11], whereas others have failed to demonstrate this [12-14] or reported controversial results [8]. A study performed on patients with NIDDM demonstrated that a lower rate constant of glucose disappearance $\left[\mathrm{K}_{\mathrm{G}}\right]$ following an intravenous glucose tolerance test, was related to a greater mortality rate in the presence of similar fasting plasma insulin levels, which suggests a higher insulin resistance in subjects who subsequently died [15].

Since hyperinsulinaemia is an index of insulin resistance, these studies suggest a role for the hpyerinsulinaemia/insulin resistance association as a predictor of IHD, at least in non-diabetic subjects. However, the degree of insulin resistance is not clearly evidenced by the 
serum insulin or C-peptide concentration, especially in NIDDM [16]. In fact, the impaired beta-cell response to hyperglycaemia, which characterises NIDDM [17, 18], reduces the significance of serum insulin or C-peptide levels as an index of insulin resistance. Therefore, only a direct evaluation of insulin sensitivity could clarify the relationship between insulin resistance and IHD, both in normal and, especially, in NIDDM patients.

Our aim was to assess whether NIDDM patients with IHD are more insulin resistant compared to patients without IHD. To evaluate the insulin sensitivity we used the ITT, a simple and inexpensive method, useful for epidemiological studies and for routine evaluation of insulin sensitivity in humans. This test shows a strong correlation with the gold standard technique of insulin sensitivity measurement, i.e. the euglycaemic, hyperinsulinaemic clamp [19-21].

\section{Subjects and methods}

\section{Subjects}

Seventy-two male out-patients with NIDDM (National Diabetes Data Group criteria) [22], 36 with and 36 without IHD, were studied. All the patients were attending our diabetic clinic and were recruited between October 1991 to January 1992, during a control visit. Subjects who were more than 75 years of age, had signs of cardiac failure, proteinuria or renal failure, liver diseases and other chronic or intercurrent illnesses were excluded. Subjects who exercised regularly or performed any other rigorous physical activity, who showed weight fluctuation or consumed more than $80 \mathrm{~g}$ alcohol per day or hypolipaemic drugs in the previous 3 months were also excluded. Subjects who had suffered myocardial infarction or who had undergone coronary angioplastic or by-pass surgery in the previous 6 months were not studied to avoid a possible influence of the therapeutic physical inactivity on insulin sensitivity.

All subjects with IHD fulfilling the selection criteria and a control group of patients without IHD were studied. All subjects were following a diet for diabetic patients composed of approximately $45 \%$ carbohydrates, $20 \%$ proteins and $35 \%$ lipids. Patients were informed about the purpose of the study and gave their informed consent to the procedure which was performed according to the Declaration of Helsinki and with the local ethical committee approval.

\section{Experimental protocol}

To determine eligibility, medical history, physical examination and a 12-lead ECG were performed. A fasting blood sample for measurement of lipids, creatinine, potassium and $\mathrm{HbA}_{1 \mathrm{c}}$ measurements was collected.

The systolic (first phase) and diastolic (fifth phase) blood pressure was measured to the nearest $2 \mathrm{~mm} \mathrm{Hg}$ using a standard sphygmomanometer by a single, trained examiner, at least $12 \mathrm{~h}$ after the last dose of any cardiovascular agent. After a 10-min rest measurements were taken three times, with the patient in the supine position. The mean of the last two measurements was considered. Subjects who fulfilled the recruitment criteria were asked to participate in an intravenous ITT within 2 weeks. Dur- ing this time period they were asked to collect two 24-h urine samples, which were then brought to the diabetic clinic. The volume was measured and aliquots immediately frozen at $-20^{\circ}$ until analysed. The presence of urinary tract infection was excluded by clinical criteria and by examination of the urinary sediment. Oral antidiabetic agents were withdrawn at least $36 \mathrm{~h}$ before the ITT to avoid any residual effect altering the steady-state of the plasma blood glucose level before the ITT. For the same reason, both long-acting and regular insulin were withdrawn at least 36 and $12 \mathrm{~h}$, respectively, before the ITT. Cardiovascular drug therapy was interrupted $12-14 \mathrm{~h}$ before testing. Three patients with IHD and two without withdrew between recruitment and the ITT. Their clinical features did not differ from the remaining patients.

ITT was performed at 08.00 hours, in the postabsorptive state. Blood samples were collected at $-30,-15$ and -1 min to confirm the glycaemia steady state and to measure serum insulin and C-peptide levels. At $0 \mathrm{~min}$, an i.v. bolus of regular insulin (0.1 IU/kg of body weight) was infused and blood samples were obtained at 3, 6, 9, 12, 15, 18, 24, $30 \mathrm{~min}$. The samples were collected in tubes containing EDTA and NaF and centrifuged for the immediate determination of plasma blood glucose levels. At the end of ITT, or in the presence of any hypoglycaemic symptom, $20 \mathrm{ml} 33 \%$ glucose solution followed by a continuous 30 min infusion of a $5 \%$ glucose solution were administered i.v.

\section{Analytical methods}

Body mass index (BMI) was calculated as weight (in $\mathrm{kg}$ ) divided by height $\left(\right.$ in $^{2}$ ). Fat distribution was evaluated using the waist to hip ratio. Measurements of the waist at the smallest abdominal circumference and of the hip at the largest gluteal circumference were taken to the nearest $0.5 \mathrm{~cm}$ [23]. Body composition was calculated from height and weight according to Hume's method [24]. Hypertension was defined on the basis of the World Health Organization criteria (systolic and/or diastolic blood pressure $\geq 160 \mathrm{~mm} \mathrm{Hg}$ and $\geq 95 \mathrm{~mm} \mathrm{Hg}$, or the current consumption of a hypotensive drug). Microalbuminuria was defined if the average of the two 24-h urinary albumin excretion measurements was greater than $30 \mathrm{mg}$ [25]. Smoking habits, past and present, were categorized as smoking more or less than 20 cigarettes per day, or having never smoked. Daily alcohol intake was stratified as either more or less than $40 \mathrm{~g}$, or no intake, assuming that the amount of alcohol in a glass of wine is $10.8 \mathrm{~g}$, in a bottle of beer ( 0.33 litre) $12.8 \mathrm{~g}$, in a measure of spirits $15.1 \mathrm{~g}$ [26]. Hypotensive therapy was grouped as possibly ameliorating (ACE inhibitors and peripheral alpha blockers) or worsening (beta blockers and thiazide diuretics) or having no effect (others) on insulin sensitivity [27]. Antidiabetic therapy was categorized as insulin, insulin plus oral hypoglycaemic agents, sulphonylurea and/or biguanide agents, and diet only treatment. IHD was diagnosed using at least one or more of the following criteria: Rose Questionnaire [28], ECG at rest (Minnesota Code 1.1-1.3, 4.1$4.4,5.1-5.3,7.1$ ) [29], echocardiography (presence of regional wall motion abnormalities) coronary angiography $(50 \%$ or greater narrowing of one of the principal coronary arteries, at least in two projections), percutaneous transluminal coronary angioplasty or coronary by-pass surgery. In the control subjects IHD was excluded by the Rose Questionnaire and ECG at rest (Minnesota Code criteria).

Plasma glucose was measured in triplicate with the glucose oxidase method [Beckmam Glucose Analyzer; Beckman, Fullerton, Calif., USA]. The intra-assay and inter-assay coefficients of variation of glycaemia were less than $1.2 \%$ and less than $1.5 \%$, respectively. Serum total cholesterol and triglycerides 
Table 1. Clinical and metabolic features of NIDDM patients with (IHD + ) and without (IHD - ) IHD

\begin{tabular}{|c|c|c|c|c|c|}
\hline \multirow[b]{2}{*}{ Age (years) } & \multicolumn{2}{|c|}{$\mathrm{IHD}+$} & \multicolumn{2}{|c|}{ IHD - } & \multirow{2}{*}{$\frac{p \text { value }}{>0.9}$} \\
\hline & $59 \pm 9$ & $(40-71)$ & $59 \pm 7$ & $(44-70)$ & \\
\hline Duration of diabetes (years) & $9.1 \pm 7.9$ & $(0.5-32)$ & $9.9 \pm 5.8$ & $(0.5-22)$ & $>0.4$ \\
\hline Body mass index $\left(\mathrm{kg} / \mathrm{m}^{2}\right)$ & $26.7 \pm 3.4$ & $(19.9-32.5)$ & $26.1 \pm 2.7$ & $(21.3-32.7)$ & $>0.4$ \\
\hline Body fat (\% body weight) & $29.9 \pm 5.1$ & $(18.6-37.2)$ & $29.5 \pm 3.7$ & $(21.5-37.5)$ & $>0.7$ \\
\hline $\mathrm{HbA}_{1 \mathrm{c}}(\%)$ & $6.4 \pm 1.5$ & $(4.5-10.3)$ & $6.5 \pm 1.4$ & $(4.3-9.8)$ & $>0.8$ \\
\hline Creatinine $(\mu \mathrm{mol} / 1)$ & $107.8 \pm 10.6$ & $(88.4-132.6)$ & $103.4 \pm 15.9$ & $(79.6-132.6)$ & $>0.16$ \\
\hline \multicolumn{5}{|l|}{ Alcohol consumption ( $n$ ) } & NS \\
\hline$>40$ g daily & \multicolumn{2}{|l|}{8} & \multicolumn{2}{|c|}{7} & \\
\hline$\leq 40$ g daily & \multicolumn{2}{|l|}{15} & \multicolumn{2}{|c|}{19} & \\
\hline no intake & \multicolumn{2}{|l|}{13} & \multicolumn{2}{|c|}{10} & \\
\hline Hypoglycaemic therapy (n) & & & & NS \\
\hline Insulin & \multicolumn{2}{|l|}{4} & \multicolumn{2}{|c|}{2} & \\
\hline \multicolumn{6}{|l|}{ Hypotensive therapy (n) } \\
\hline \multicolumn{6}{|l|}{ ACE-inhibitors and/or } \\
\hline peripheral alpha-blockers & \multicolumn{2}{|l|}{5} & \multicolumn{2}{|c|}{3} & \\
\hline \multicolumn{6}{|l|}{ Beta-blockers and/or } \\
\hline thiazides & \multicolumn{2}{|l|}{16} & \multicolumn{2}{|c|}{4} & \\
\hline Others & \multicolumn{2}{|l|}{6} & \multicolumn{2}{|c|}{1} & \\
\hline Total $(\%)$ & 27 & $(75)$ & & $(22)$ & $<0.001$ \\
\hline Diagnosis of IHD (Rose & & & & & \\
\hline Questionnaire and/or ECG & & & & & \\
\hline at rest) confirmed by & & & & & \\
\hline other diagnostic procedures ( & & & & & \\
\hline
\end{tabular}

Data are expressed as mean $\pm \mathrm{SD}$ (range)

were measured enzymatically (coefficients of variation intraand inter-assay $1.7 \%$ and $2.2 \%$ for cholesterol, $2.1 \%$ and $2.8 \%$ for triglycerides, respectively). HDL cholesterol was measured enzymatically after precipitation of the other lipoproteins (coefficients of variation intra- and inter-assay $2.7 \%$ and $3.1 \%$, respectively). LDL cholesterol was calculated using the Friedwald formula only if triglyceride levels were less than $45.2 \mathrm{mmol} / 1[30]$. Creatinine was measured using the Jaffé method (coefficients of variation intra- and inter-assay $2.5 \%$ and $3.2 \%$, respectively). Potassium was measured by an indirect potentiometric method (coefficients of variation intra- and inter-assay $1.3 \%$ and $3.3 \%$, respectively). $\mathrm{HbA}_{1 \mathrm{c}}$ was determined by ion exchange automatized chromatography (coefficients of variation intra- and interassay 1.1 and $1.2 \%$, respectively, normal value $<5.3 \%$ ). C-peptide was determined by radioimmunoassay [31] (RIA-coat CPeptide; Byk-Sangtec Diagnostica, Dietzenbach, Germany, coefficients of variation intra- and inter-assay $6 \%$ and $10 \%$, respectively). Insulin was measured by enzyme immunoassay (Medgenix-Ins-Easi; Medgenix Diagnostics, Brussels, Belgium, coefficients of variation intra- and inter-assay of $7 \%$ and $11 \%$, respectively) [32]. Albuminuria was measured by radioimmunoassay (Diagnostic Products Corporation, Los Angeles, Calif., USA, coefficients of variation intra- and inter-assay $5 \%$ and $10 \%$, respectively) [33].

The ITT's K index ( $\mathrm{K}_{\mathrm{ITT}}$ ) of insulin sensitivity was calculated as previously described [20]. Briefly, the $\mathrm{K}$ value was the ratio between 0.693 and $t_{1 / 2}$, where $t_{1 / 2}$ is the time necessary to reduce the glycaemic value by one half at $-1 \mathrm{~min}$. $T_{1 / 2}$ was calculated from the slope of least square analysis of the glycaemic concentrations, starting at the 3 rd min until the 15 th min after $i$. v. insulin injection. ITT was reproducible in eight NIDDM subjects on whom the test was performed twice within 2 weeks. The mean $\mathrm{K}_{\mathrm{ITT}}$ values $( \pm \mathrm{SEM}$ ) were $2.83 \pm 0.26$ and $2.89 \pm 0.35 \%$ per min with a coefficient of variation of $6 \pm 2 \%$.

\section{Statistical analysis}

Triglycerides and serum insulin levels were log transformed for their skewed distribution before analysis, and then reconverted for data presentation. Two-tailed Student's $t$-test for unpaired data was utilized to compare the two groups for the continuous variables. Two-way analysis of variance for repeated measures was used to compare basal glycaemic plasma levels between the two groups. Chi-square with Yates correction was used to compare the two groups for discrete variables. Step-wise logistic regression analysis was performed to evidence the features independently related to IHD. A forward step-wise selection criterium was chosen, with a cut-off level of significance of 0.05 , to enter in the model. The likelihood-ratio test was used for determining variables to be removed from the model, with a cut-off value of 0.1 . In this analysis the negative of the $\mathrm{K}_{\mathrm{ITT}}$ values were used to evidence a direct relation with the insulin resistance level. 


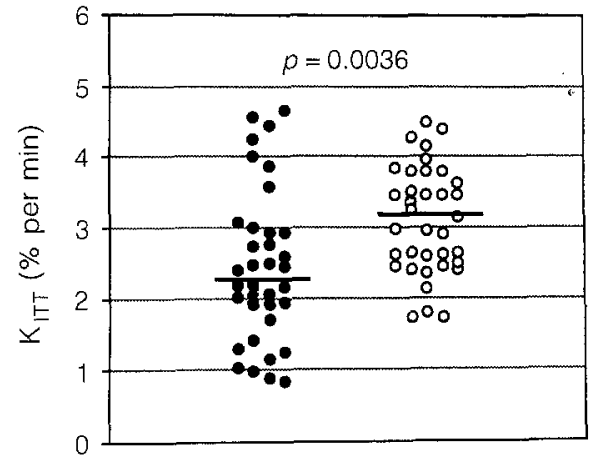

Fig. 1. $K_{\Gamma T}$ index of insulin sensitivity ( $\%$ per min) in patients with (closed circles) and without IHD (open circles). The horizontal bars indicate mean values

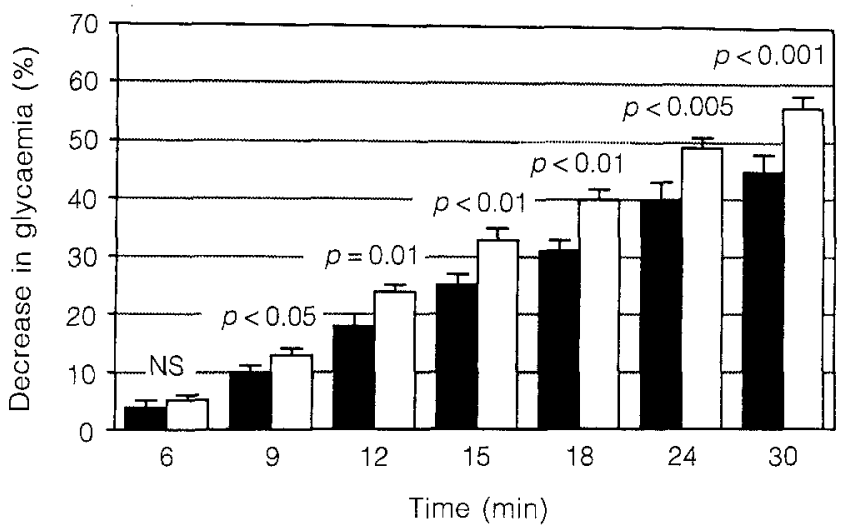

Fig. 2. Decrease (in \%) of basal glycaemic levels after insulin injection in patients with (shaded bars) and without IHD (open bars). Mean \pm SEM are shown

Multiple linear regression analysis was used to relate the clinical and metabolic parameters to the age of the clinical onset of IHD.

A $p$ value less than 0.05 was considered as statistically significant. Data were analysed using SPSS/PC + statistical package. The results are expressed as mean \pm SEM unless otherwise stated.

\section{Results}

Patients with and without IHD could be matched for age (within 6 years) and for known duration of diabetes (within 5 years, with four exceptions) (Table 1). Moreover, the two groups showed similar BMI, body composition, alcohol intake, type of hypoglycaemic therapy, glycaemic control and plasma potassium levels, whereas more patients with IHD were taking antihypertensive drugs $(p<0.001)$, in particular beta blockers or thiazide diuretics or both (Table 1). Glycaemia was in the steady state during the $30 \mathrm{~min}$ before ITT and similar values were observed between the two groups ($30 \mathrm{~min}: \quad 9.7 \pm 0.5$ and $9.8 \pm 0.4 \mathrm{mmol} / \mathrm{l} ; \quad-15 \mathrm{~min}$ : $9.5 \pm 0.5$ and $9.8 \pm 0.4 \mathrm{mmol} / \mathrm{l} ;-1 \mathrm{~min}: 9.6 \pm 0.5$ and $9.8 \pm 0.4 \mathrm{mmol} / \mathrm{l}$, subjects with and without $\mathrm{IHD}$, respectively). No patient had to interrupt the ITT due to hypoglycaemic symptoms.
Table 2. IHD risk factors levels in NIDDM patients with $(\mathrm{IHD}+)$ and without (IHD - ) IHD

\begin{tabular}{|c|c|c|c|}
\hline & $\mathrm{IHD}+$ & $\mathrm{IHD}-$ & $p$ value \\
\hline $\begin{array}{l}\mathrm{K}_{\mathrm{ITT}} \text { index } \\
(\% \text { per } \min )\end{array}$ & $2.45 \pm 0.18$ & $3.12 \pm 0.13$ & 0.0036 \\
\hline $\begin{array}{l}\text { Total cholesterol } \\
(\mathrm{mmol} / \mathrm{l})\end{array}$ & $6.09 \pm 0.2$ & $5.39 \pm 0.16$ & 0.011 \\
\hline $\begin{array}{l}\text { LDL cholesterol } \\
(\mathrm{mmol} / \mathrm{l})\end{array}$ & $3.86 \pm 0.18$ & $3.32 \pm 0.13$ & 0.010 \\
\hline $\begin{array}{l}\text { HDL cholesterol } \\
(\mathrm{mmol} / \mathrm{l})\end{array}$ & $1.29 \pm 0.05$ & $1.29 \pm 0.05$ & NS \\
\hline $\begin{array}{l}\text { Triglycerides } \\
(\mathrm{mmol} / \mathrm{l})\end{array}$ & $2.05 \pm 0.18$ & $1.63 \pm 0.16$ & 0.09 \\
\hline Insulin (pmol/1) & $79.6 \pm 10.8$ & $71 \pm 12.2$ & NS \\
\hline C-peptide (nmol/l) & $0.97 \pm 0.07$ & $0.85 \pm 0.05$ & NS \\
\hline Waist to hip ratio & $0.98 \pm 0.01$ & $0.97 \pm 0.01$ & NS \\
\hline \multirow{2}{*}{$\begin{array}{l}\text { Smokers }(n, \%) \\
>20 \text { cigarettes } \\
\text { per day }\end{array}$} & $29(81)$ & $25(69)$ & NS \\
\hline & $16(44)$ & $12(33)$ & NS \\
\hline $\begin{array}{l}\text { Systolic blood } \\
\text { pressure (mm Hg) }\end{array}$ & $156 \pm 3$ & $151 \pm 4$ & NS \\
\hline $\begin{array}{l}\text { Diastolic blood } \\
\text { pressure (mmHg) }\end{array}$ & $91 \pm 2$ & $91 \pm 1$ & NS \\
\hline $\begin{array}{l}\text { Prevalence of } \\
\text { hypertension } n(\%)\end{array}$ & $30(83)$ & $16(44)$ & 0.001 \\
\hline $\begin{array}{l}\text { Prevalence of micro- } \\
\text { albuminuria } n(\%)\end{array}$ & $13(36)$ & $7(19)$ & 0.11 \\
\hline
\end{tabular}

With respect to subjects without IHD, patients with IHD showed a lower $\mathrm{K}_{\mathrm{ITT}}$ index of insulin sensitivity $(2.45 \pm 0.18$ vs $3.12 \pm 0.13 \%$ per min, $p<0.004$ ) (Fig. 1 , Table 2) and a lower percent glycaemic decrement after insulin infusion as compared with basal values, with a statistical significance starting from as early as $9 \mathrm{~min}$ and increasing until $30 \mathrm{~min}(p<0.05-0.001)$ (Fig. 2). Total ( $p=0.011)$ and LDL $(p=0.010)$ serum cholesterol levels, the latter calculated with the Friedwald formula (in all but one patient due to triglyceride plasma levels greater than $45.2 \mathrm{mmol} / \mathrm{l}$ ), were also higher in the IHD group. No significant differences were found for insulin, C-peptide, triglycerides $(p=0.09)$, HDL cholesterol and creatinine serum concentrations, and waist to hip ratio (Table 2). Systolic and diastolic blood pressure were not different between the two groups (Table 2). However, the prevalence of hypertension was higher in patients with IHD compared to patients without IHD $(p=0.001)$ (Table 2), since more patients with IHD were undergoing antihypertensive therapy $(p<0.001)$ (Table 1$)$.

Although the prevalence of microalbuminuria was two-fold higher in the group with IHD (36\% vs 19\%), the difference was not statistically significant due to the small number of microalbuminuric patients in both groups $(p=0.11)$ (Table 2). Smoking habits were similar in the two groups (Table 2). 
Table 3. Step-wise logistic regression analysis showing the features independently related with the presence of IHD

\begin{tabular}{lccc}
\hline & Odds ratio & $95 \%$ CI & $p$ value \\
\hline Hypertension & 8.17 & $6.86-9.48$ & 0.002 \\
Insulin resistance & 2.57 & $1.87-3.28$ & 0.008 \\
Total cholesterol & 1.02 & $1.005-1.035$ & 0.015 \\
Body mass index & 0.79 & $0.67-0.97$ & 0.049 \\
\hline
\end{tabular}

Step-wise logistic regression analysis was performed to assess if the lower insulin sensitivity characterizing the patients with IHD was a feature independent from other possible confounding factors. The following independent variables, as possible risk factors or markers of IHD, were included in the model: age, duration of diabetes, $\mathrm{HbA}_{1 c}$, BMI, waist to hip ratio, total and HDL cholesterol, triglycerides, $\mathrm{K}_{\mathrm{ITT}}$ index of insulin sensitivity, insulin, C-peptide and creatinine as continuous variables; hypertension, microalbuminuria, smoking habits, alcohol consumption, type of hypotensive and hypoglycaemic therapy as discrete variables. Only insulin resistance, represented by the $\mathrm{K}_{\mathrm{ITT}}$ index, $(p=0.008)$, hypertension $(p=0.002)$, higher total serum cholesterol levels $(p=0.015)$ and a lower BMI $(p=0.049)$ were independently associated with IHD (Table 3). When the type of hypotensive therapy was forced in the model, only insulin resistance, hypertension and total cholesterol remained independently related to IHD $(p<0.02)$, BMI achieving only a borderline significance $(p=0.058)$. When all variables were entered simultaneously, only insulin resistance $(p=0.023)$ and hypertension $(p=0.034)$ remained independently related to IHD, total cholesterol and BMI revealing borderline significance $(p=0.09$ and $p=0.11$, respectively).

To directly evaluate the possible influence of beta blockers and/or thiazide diuretics on insulin sensitivity, patients taking these drugs were excluded from both groups. $\mathrm{K}_{\mathrm{ITT}}$ index remained significantly lower in IHD patients and showed values similar to those of each group as a whole $(2.54 \pm 0.23$ vs $3.10 \pm 0.14 \%$ per min, patients with and without IHD, respectively, $p=0.033$ ).

Finally, we used the multiple linear regression analysis to explore the possibility of any relationship between certain metabolic features and the age of the clinical onset of IHD ( $54 \pm 2$ years). From the analysis three patients diagnosed only by ECG at rest were excluded, whose age at IHD onset could not be determined by subjective symptoms. Blood pressure was also excluded from the independent variables, since almost all the remaining patients were on antihypertensive therapy ( 27 of 33 patients, $82 \%$ ). After adjustment for age and duration of diabetes, $\mathrm{K}_{\mathrm{ITT}}$ index was the only metabolic feature related to the age of clinical onset of IHD $(p=0.006)$. No significant relationship was found with BMI, waist to hip ratio, total and HDL cholesterol, triglycerides, C-peptide and serum insulin levels. A significant association between $\mathrm{K}_{\mathrm{ITT}}$ index and the age of clinical onset of IHD remained after adjustment for all the above-mentioned variables $(p<0.015)$. The self-reported body weight was similar at onset of IHD and at entry to the study $(80 \pm 2$ vs $79 \pm 2 \mathrm{~kg}$, respectively, $p=\mathrm{NS}$ by two-tailed $t$-test for paired data).

\section{Discussion}

Our study demonstrates, for the first time, employing a direct measurement of insulin sensitivity, that NIDDM patients with IHD are more insulin resistant than NIDDM patients without IHD. The different insulin sensitivity cannot be accounted for by age, duration of diabetes, BMI or composition, glycaemic control, serum potassium, alcohol intake or hypoglycaemic therapy, because these features were similar in the two groups. Body composition was evaluated by means of an indirect method; however, lean body mass, calculated using Hume's formula, shows a highly significant correlation with that derived from measurement of total body water, especially in men [24]. Moreover, even if our indirect evaluation of body fat should not correspond exactly to the real value, we do not believe that it could differ so much as to shift the actual $p$ value into the statistical significance range. The amount of physical activity was not precisely quantified and, therefore, a difference between the two groups could not be excluded; however, several points suggest that this is unlikely; in fact, no subject in either group had a job involving heavy physical duties, nor did they exercise regularly. Furthermore, the study was performed at least 6 months after the onset of myocardial infarction or angioplastic or by-pass surgery when all IHD patients had returned to their usual activities, with no patient suffering from unstable angina or stable angina at low threshold. Finally, three clinical features significantly related to the level of physical activity, i. e. HDL cholesterol, waist to hip ratio and percent of body fat $[34,35]$, were similar in the two groups. The only difference was the higher prevalence of hypotensive therapy in patients with IHD. However, both the multivariate analysis and the direct exclusion of subjects taking beta blockers and/or thiazide diuretics confirm the different response to insulin by the two groups.

Since the criteria for the identification of IHD were more restrictive than those used to exclude the disease, some misclassification of subjects without IHD could have occurred. However, the failed identification of IHD in some control subjects would result in an underestimation of both the difference noticed between the two groups and the odds ratio of the logistic regression analysis. This could explain, for instance, the low odds ratio of total cholesterol. However, it should be kept in mind that several studies in NIDDM did not show an indepedent association between cholesterol and IHD at 
the multivariate analysis [36]. Finally, our study agrees with recent reports showing a greater insulin resistance in non-diabetic patients with peripheral asymptomatic atherosclerosis [37], ischaemic ECG changes [38], angiographic diagnosis of IHD [39], microvascular angina [40] compared to normal subjects, as well as in insulindependent diabetic patients who died of cardiovascular diseases compared to those who survived [41].

To evaluate insulin sensitivity we used the ITT, with the modification suggested by Bonora et al. [20]. Even if this test is not the "gold standard" method to measure insulin sensitivity, the rate of glycaemic decrement after i.v. insulin injection shows a high correlation with the insulin-mediated glucose disposal measured during a euglycaemic-hyperinsulinaemic clamp [19-21]. Moreover, the test was reproducible both by our group and others $[20,21,42]$. Therefore, we believe that it could be useful for epidemiological studies and for a routine measurement of insulin sensitivity.

The step-wise multiple logistic regression analysis shows an independent relationship between insulin resistance and IHD. Moreover, analysing the age of the clinical onset of IHD and the actual levels of some metabolic features we found a positive, independent relationship between $\mathrm{K}_{\mathrm{ITT}}$ and the age of onset of IHD. Although these data suggest an independent association between insulin resistance and IHD, this possibility should be considered with caution. In fact, other IHD risk factors, possibly explaining the association between insulin resistance and IHD, i.e. clotting factors [43], were not evaluated. Furthermore, the good glycaemic control showed by our patients could have partially corrected other metabolic alterations usually associated in the insulin resistance syndrome, i.e. triglycerides and HDL-cholesterol [44, 45]. Finally, and most important, the cross-sectional design of our study does not enable us to establish a time-relationship between insulin resistance and both IHD and other cardiovascular risk factors or markers. For instance, in the prediabetic state, insulin resistance is balanced by higher serum insulin levels, that progressively decline with the development of the diabetic disease [46]. Therefore, before the onset of NIDDM, IHD patients could have been exposed to higher insulin levels than subjects without IHD, thus favouring the subsequent development of IHD [47]. However, since the link between hyperinsulinaemia and insulin resistance is broken at the appearance of NIDDM, only the degree of insulin resistance could be an index of the past hyperinsulinaemia and a marker of the presence of IHD and, possibly, of a greater probability of its onset. Nevertheless, our results are the first direct evidence of the possible extension of the role of insulin resistance not only as a factor promoting the development of NIDDM [46] but also as a marker of its more important complication, the macrovascular disease, and in particular IHD.

Patients with NIDDM show a 2-4 fold increase in the prevalence of IHD compared to non-diabetic sub- jects $[48,49]$ and this difference is not completely accounted for by the alteration of the conventional cardiovascular risk factors $[48,50]$. A common metabolic defect in NIDDM is the presence of insulin resistance [17], which seems to be the primum movens of the natural course of the disease [46]. Bearing this in mind, our results suggest a contribution by insulin resistance to explain, at least in part, both the gap between the observed and the expected cardiovascular events on the basis of the conventional atherogenic risk factors, and the higher incidence of cardiovascular disease in NIDDM patients compared to non-diabetic subjects.

In conclusion, in NIDDM, patients with IHD are more insulin resistant than patients without IHD and this difference seems independent from other cardiovascular risk factors. However, prospective studies, involving a population with a high risk of developing NIDDM, need to confirm our results and to define the time-relationship and the effect of insulin resistance on other cardiovascular risk factors and on cardiovascular disease.

Acknowledgements. The authors are indebted to C. Francescutti for statistical advice; to Dr. G. F. Santini, Department of Microbiology and Immunology, for the biochemical analysis; to Ms. A. Leech-Peduto for her invaluable help with linguistic revision. This work was presented in part, in abstract form, at the 28th Annual Meeting of the European Association for the Study of Diabetes, in Prague, Czechoslovakia, 1992.

\section{References}

1. Fontbonne AM, Charles MA, Thibult Net al. (1991) Hyperinsulinaemia as a predictor of coronary heart disease mortality in a healthy population: the Paris Prospective Study, 15-year follow-up. Diabetologia 34: 356-361

2. Pyörälä K (1979) Relationship of glucose tolerance and plasmainsulin to the incidence of coronary heart disease: results of two population studies in Finland. Diabetes Care 2: 131-141

3. Welborn TA, Wearne K (1979) Coronary heart disease incidence and cardiovascular mortality in Busselton with reference to glucose and insulin concentrations. Diabetes Care 2: $154-160$

4. Hamsten A, Efendic S, Walldius G, Szamosi A, De Faire U (1987) Glucose tolerance and insulin response to glucose in non diabetic young male survivors of myocardial infarction. Am Heart J 113: 917-927

5. Lichtenstein MJ, Yarnell JWG, Elwood PC et al. (1987) Sex hormones insulin, lipids and prevalent ischemic heart disease. Am J Epidemiol 126: 647-657

6. Hughes LO, Cruickshank JK, Wright J, Raftery EB (1989) Disturbances of insulin in British Asian and white men surviving myocardial infarction. BMJ 299: 4537-4541

7. Modan M, Jacob O, Karasik K et al. (1991) Hyperinsulinaemia, sex, and risk of atherosclerotic cardiovascular disease. Circulation 84: 1165-1175

8. Ronnemaa T, Laakso M, Pyörälä K, Kallio V, Puukka P (1991) High fasting plasma insulin is an indicator of coronary heart disease in non-insulin-dependent diabetic patients and nondiabetic subjects. Arterioscler Thromb 11: 80-90

9. Hillson RM, Hockaday TDR, Mann JI, Newton DJ (1984) Hyperinsulinaemia is associated with development of elec- 
trocardiographic abnormalities in diabetics. Diabetes Res 1: 143-149

10. Janka HU, Ziegler AG, StandlE, Menhert H (1987) Daily insulin dose as a predictor of macrovascular disease in insulintreated non-insulin dependent diabetics. Diabet Metab 13: 359-364

11. Bergstrom RW, Leonetti DL, Newell-Morris LL, Shuman WP, Wahl PW, Fujimoto WY (1990) Association of plasma triglyceride and C-peptide with coronary heart disease in Japanese-American Men with a high prevalence of glucose intolerance. Diabetologia 33: 489-496

12. Fontbonne $A$, Thibult $\mathrm{N}$, Eschwège $\mathrm{E}$, Ducimetière $\mathrm{P}$ (1992) Body fat distribution and coronary heart disease mortality in subjects with impaired glucose tolerance or diabetes mellitus: the Paris Prospective Study, 15-year follow-up. Diabetologia 35: 464-468

13. Jarrett RJ, McCartney P, Keen H (1982) The Bedford Study: Ten years mortality rates in newly diagnosed diabetes, borderline diabetics and normoglycaemic controls and risk indices for coronary heart disease in borderline diabetics. Diabetologia 22: 79-84

14. Uusitupa MIJ, Niskanen LK, Siitonen O, Voutilainen E, Pyorala K (1990) 5-year incidence of atherosclerotic vascular disease in relation to general risk factors, insulin level, and abnomalities in lipoprotein composition in non-insulin-dependent diabetic and non diabetic subjects. Circulation 82: $27-36$

15. Coppack SW, Doll HA, Pim B, Hockaday TDR (1990) Intravenous glucose tolerance and mortality in non-insulin-dependent diabetes mellitus. Quart J Med 277: 451-460

16. Laakso M (1993) How good a marker is insulin level for insulin resistance? Am J Epidemiol 137: 959-965

17. De Fronzo RA (1988) The triumvirate: beta cell, muscle, liver: a collusion responsible for NIDDM. Diabetes 37:667-687

18. Porte DJ (1990) Banting Lecture 1990: B-cell in type II diabetes mellitus. Diabetes 40: 166-180

19. Del Prato S, Ferrannini E, De Fronzo RA (1986) Evaluation of insulin sensitivity in man. In: Clark WL, Lamer J, Pohl SC (eds) Methods in diabetes research, Wiley and Sons, New York, pp 39-43

20. Bonora E, Moghetti P, Zancanaro Cet al. (1989) Estimates of in vivo insulin action in man: comparison of insulin tolerance tests with euglycemic and hyperglycemic glucose clamp studies. J Clin Endocrinol Metab 68:374-378

21. Akinmokun A, Selby PL, Ramaiya K, Alberti KGMM (1992) The short insulin tolerance test for determination of insulin sensitivity: a comparison with the euglycaemic clamp. Diabetic Med 9: 432-437

22. National Diabetes Data Group (1979) Classification and diagnosis of diabetes mellitus and other categories of glucose intolerance. Diabetes 28: 1039-1057

23. Kissebah AH, Peiris AN (1989) Biology of regional body fat distribution: relationship to non-insulin-dependent diabetes mellitus. Diabetes Metab Rev 5: 83-109

24. Hume R (1966) Prediction of lean body mass from height and weight. J Clin Pathol 19: 389-391

25. Mogensen CE, Chacati A, Christensen CK et al. (1986) Microalbuminuria: an early marker of renal involvement in diabetes. Uremia Invest 9: 85-95

26. Giovannucci E, Colditz G, Stampfer MJ et al. (1985) The assessment of alcohol consumption by a simple self-administered questionnaire. Am J Epidemiol 133: 810-817

27. Prisant LM, Carr AA (1992) Antihypertensive drug therapy and insulin resistance. Am J Hypertens 5: 775-777

28. Rose GA (1962) The diagnosis of ischemic heart pain and intermittent claudication in field surveys. Bull WHO 27: 645658
29. Rose GA, Blackburn H (1968) Cardiovascular survey methods. WHO Monograph Series, No 56 World Health Organization, Geneva

30. Friedwald WT, Levy R, Fredrickson DS (1972) Estimation of serum low density lipoprotein without the use of a preparative ultracentrifuge. Clin Chem 18: 499-502

31. Heding L (1975) Radioimmunological determination of human C-peptide in serum. Diabetologia 11: 541-548

32. Burgi W, Briner M, Franken N, Kessler A-Ch (1988) One step sandwich enzyme immunoassay for insulin using monoclonal antibodies. Clin Biochem 21: 311-314

33. Keen H, Chlouverakis C (1963) An immunoassay for urinary albumin at low concentrations. Lancet II: 913-916

34. Wood PD, Stefanick ML, Dreon DMet al. (1988) Changes in plasma lipids and lipoprotein in overweight men during weight loss through dieting as compared with exercise. $\mathrm{N}$ Engl J Med 319: 1173-1179

35. Coon PJ, Rogus EM, Drinkwater D, Muller DC, Goldberg AP (1992) Role of body fat distribution in the decline in insulin sensitivity and glucose tolerance with age. J Clin Endocrinol Metab 75: 1125-1132

36. Fontbonne A (1991) Relationship between diabetic dyslipoproteinaemia and coronary heart disease risk in subjects with non-insulin dependent diabetes mellitus. Diabetes Metab Rev 3: 179-189

37. Laakso M, Sarlund H, Salonen R et al. (1991) Asymptomatic atherosclerosis and insulin resistance. Arterioscler Thromb 11: 1068-1076

38. Sheu WHH, Jeng CY, Shieh SM et al. (1992) Insulin resistance and abnormal electrocardiograms in patients with high blood pressure. Am J Hypertens 5: 444-448

39. Bressler P, Bailey S, Saad R, De Fronzo RA (1992) Insulin resistance and coronary artery disease (CAD): the missing link. Diabetes 41 [Suppl 1]: 24A (Abstract)

40. Botker HE, Moller N, Ovesen P et al. (1993) Insulin resistance in microvascular angina (syndrome X). Lancet 342 : $136-140$

41. Martin FIR, Hopper JL (1987) The relationship of acute insulin sensitivity to the progression of vascular disease in longterm type 1 (insulin-dependent) diabetes mellitus. Diabetologia 30: 149-153

42. Hirst S, Phillips DIW, Vines SK, Clark PM, Hales CN (1993) Reproducibility of the short insulin tolerance test. Diabetic Med 10: 839- 842

43. Gough SCL, Grant PJ (1991) The fibrinolytic system in diabetes mellitus. Diabetic Med 8: 898-905

44. Reaven GM (1988) Banting Lecture 1988: Role of insulin resistance in human disease. Diabetes 37: 1595-1607

45. De Fronzo RA, Ferrannini E (1991) Insulin resistance. A multifaceted syndrome responsible for NIDDM, obesity, hypertension, dislipidemia, and atherosclerotic cardiovascular disease. Diabetes Care 18: 173-194

46. Martin BC, Warram JH, Krolewski AS, Bergman RN, Soeldner JS, Kahn CR (1992) Role of glucose and insulin resistance in development of type 2 diabetes mellitus: results of a 25-year follow-up study. Lancet 340: 925-929

47. Stout RW (1990) Insulin and atheroma: 20-yr perspective. Diabetes Care 13: 631-654

48. Pyörälä K, Laakso M, Uusitupa M (1987) Diabetes and atherosclerosis: an epidemiologic view. Diabetes Metab Rev 3: 463-524

49. Panzram G (1987) Mortality and survival in type 2 (non-insulin-dependent) diabetes mellitus. Diabetologia 30:123-131

50. Kannel WB, D'Agostino RB, Wilson PWF, Belanger AJ, Gagnon DR (1990) Diabetes, fibrinogen, and risk of cardiovascular disease: The Framingham experience. Am Heart J 120: $672-676$ 